\title{
Integrated assessment model for climate change in China
}

\author{
Tadepalli S. Murty ${ }^{1}$
}

Published online: 2 May 2018

(c) Springer Science+Business Media B.V., part of Springer Nature 2018

Climate change is the most complicated global environmental problem and one of the greatest threats facing humanity nowadays. Without concerted action, the impacts of climate change could catastrophically damage our world (Mastrandrea and Schneider 2004). Since climate change is a complex collection of political, economic, environmental and even moral issues rather than a purely scientific issue over the last few decades, the corresponding research has to be interdisciplinary and multifaceted (Wei et al. 2015). Integrated assessment model (IAM) is the mainstream methodological approach in climate change research (Yang et al. 2016). They aim to describe the complex relations between environmental, social and economic factors that determine future climate change and the effectiveness of climate change (van Vuuren et al. 2011). IAMs draw knowledge and strengths from various disciplines related to climate change; contributions from each discipline rely on the mathematical representations of certain relationships connected to climate change; disciplinary components are linked through a unified modeling platform(s). In particular, IAMs for climate change usually involve socioeconomic components as well as natural sciences components. One of the earliest IAM models is the Dynamic Integrated Model of Climate and the Economy (DICE model), which is a globally aggregated model integrating a general equilibrium model of the global economy with a climate system including emissions, concentrations, climate change, impacts and optimal policy (Nordhaus 1992, 1994). In order to improve the realism of integrated assessments by lodging policy making at the more appropriate national level, the Regional Integrated

The invited paper that is the subject of this editorial can be found at https://doi.org/10.1007/s11069-0183297-9.

Tadepalli S. Murty

tadmurty@gmail.com

1 Department of Civil Engineering, University of Ottawa, Ottawa, Canada 
model of Climate and Economy (RICE model) is developed by Nordhaus and Yang (1996). Since then, most researchers in climate change utilize IAMs directly or indirectly.

IAMs have played a significant role in assessing various greenhouse gas (GHG) mitigation policies and climate impacts. In fact, conclusions in the Intergovernmental Panel on Climate Change (IPCC) Assessment Reports are drawn substantially from numerous IAMs (IPCC 2014). The four Representative Concentration Pathways (RCPs)-RCP 2.6, RCP 4.5, RCP 6.0 and RCP 8.5-are, respectively, obtained on the basis of four IAMs: IMAGE model developed by Netherlands Environmental Assessment Agency (PBL) (van Vuuren et al. 2017), MiniCAM model developed by Pacific Northwest National Laboratory (PNNL) (Calvin et al. 2017), AIM model developed by National Institute for Environmental Studies (NIES) (Fujimori et al. 2017), and MESSAGE model developed by International Institute for applied systems analysis (IIASA) (Fricko et al. 2017). The region classification in the IAMs is usually determined by the economic scale, carbon emissions, the availability of key data and the affiliations of developers. Most IAMs cannot describe developing regions as accurately as developed regions. It is difficult for existing IAMs to guide the mitigation in developing regions. However, carbon emission mitigation in devolving regions is critical, because the proportions of carbon emissions from developing regions have been increasing. Therefore, there is an urgent need to develop an IAM which can describe developing regions more accurately.

The climate change research team from China-Center for Energy and Environmental Policy Research, Beijing Institute of Technology (CEEP-BIT)—developed the China's Climate Change Integrated Assessment Model (C ${ }^{3}$ IAM). China occupies $18.8 \%$ of global populations, $24 \%$ of global energy consumption, and $25 \%$ of global carbon emissions. Although China is usually viewed as a homogenous entity in IAMs, it is a vast country with great regional variations in economic development, resource endowments, population and lifestyles (Mi et al. 2017). Compared to existing IAMs, the $C^{3}$ IAM can describe developing regions more accurately, especially for China and its provinces. The $\mathrm{C}^{3} \mathrm{IAM}$, which integrates the economic optimum growth, global general equilibrium, revised earth system (C ${ }^{3}$ IAM/BCC_CSM model, which is one of the earth system models that participated in CMIP5 simulations for the IPCC AR5), land-use and impact models, dynamically captures the long-term optimal economic growth and climate change mitigation and adaptation. Compared with other IAMs, $C^{3}$ IAM pays more attention to clarify the comprehensive impacts of climate change and it has a better performance in the following various aspects: more in-depth depiction of China, extension of economic model, realizing the hard link between the earth and socioeconomic systems.

The $C^{3}$ IAM is applied to assess the climate change under shared socioeconomic pathways (SSPs) in the context of with and without intended nationally determined contributions (INDCs). Long-term difficulties are recognized for keeping the warming well below $2{ }^{\circ} \mathrm{C}$ and pursue efforts toward $1.5{ }^{\circ} \mathrm{C}$ target even under INDCs. It is suggested that Global Stake holders should follow-up, and even stricter reduction targets are required when countries put forward their INDCs targets after 2020, especially from major emitters like China, USA, India, Eastern European CIS (The Commonwealth of the Independent States, most of the former Soviet republics are members, excluding Russian Federation (EES). Significant reduction targets are also expected from Western Europe, Asia, Middle East, Africa (MAF) and South America. This work further contributes to the integration between the earth sciences and socioeconomic systems, as well as extending the economic models by coupling the global CGE model with the economic optimum growth model. As Editor-in-Chief, I am very pleased to see this invited paper published in Natural Hazards being the very first invited paper in the 30 -year history of the journal. 


\section{References}

Calvin K, Bond-Lamber B, Clarke L et al (2017) SSP4: a world of deepening inequality. Global Environ Change 42:284-296

Fricko O, Havlik P, Rogelj J et al (2017) The marker quantification of the shared socioeconomic pathway 2: a middle-of-the-road scenario for the 21st century. Global Environ Change 42:251-267

Fujimori S, Hasegawa T, Masui T et al (2017) SSP3: aim implementation of shared socioeconomic pathways. Global Environ Change 42:268-283

IPCC (2014) Climate change 2014: mitigation of climate change. Contribution of working group III to the fifth assessment report of the intergovernmental panel on climate change. Cambridge University Press, Cambridge

Mastrandrea MD, Schneider SH (2004) Probabilistic integrated assessment of "dangerous" climate change. Science 304(5670):571-575. https://doi.org/10.1126/science.1094147

Mi Z, Meng J, Guan D et al (2017) Chinese $\mathrm{CO}_{2}$ emission flows have reversed since the global financial crisis. Nat Commun 8:1712

Nordhaus WD (1992) The "DICE" Model: background and structure of a dynamic integrated climateeconomy model of the economics of global warming. (Cowles Foundation Discussion Papers). Yale University

Nordhaus WD (1994) Expert opinion on climatic change. Am Sci 82:45-51

Nordhaus WD, Yang ZL (1996) A regional dynamic general-equilibrium model of alternative climatechange strategies. Am Econ Rev 86:741-765

van Vuuren DP, Lowe J, Stehfest E et al (2011) How well do integrated assessment models simulate climate change? Clim Change 104:255-285

van Vuuren DP, Stehfest E, Gernaat DE et al (2017) Energy, Land-use and greenhouse gas emissions trajectories under a green growth paradigm. Global Environ Change 42:237-250

Wei YM, Mi ZF, Huang ZM (2015) Climate policy modeling: an online SCI-E and SSCI based literature review. Omega 57:70-84

Yang ZL, Wei YM, Mi ZF (2016) Integrated assessment models (IAMs) for climate change. Oxf Bibliogr. https://doi.org/10.1093/OBO/9780199363445-0043 